\title{
Stardust Entry Reconstruction
}

\author{
Prasun N. Desai ${ }^{*}$ and Garry D. Qualls ${ }^{\dagger}$ \\ NASA Langley Research Center, Hampton, VA, 23681-2199
}

\begin{abstract}
An overview of the reconstruction analyses performed for the Stardust capsule entry is described. The results indicate that the actual entry was very close to the pre-entry predictions. The capsule landed $8.1 \mathrm{~km}$ north-northwest of the desired target at Utah Test and Training Range. Analyses of infrared video footage and radar range data (obtained from tracking stations) during the descent show that drogue parachute deployment was $4.8 \mathrm{~s}$ later than the pre-entry prediction, while main parachute deployment was $19.3 \mathrm{~s}$ earlier than the pre-set timer indicating that main deployment was actually triggered by the backup baroswitch. Reconstruction of a best estimated trajectory revealed that the aerodynamic drag experienced by the capsule during hypersonic flight was within $1 \%$ of pre-entry predications. Observations of the heatshield support the pre-entry estimates of small hypersonic angles of attack, since there was very little, if any, charring of the shoulder region or the aftbody. Through this investigation, an overall assertion can be made that all the data gathered from the Stardust capsule entry were consistent with flight performance close to nominal pre-entry predictions. Consequently, the design principles and methodologies utilized for the flight dynamics, aerodynamics, and aerothermodynamics analyses have been corroborated.
\end{abstract}

\section{Nomenclature}

$\begin{array}{ll}\text { BET } & =\text { Best Estimated Trajectory } \\ \text { GRAM } & =\text { Global Reference Atmospheric Model } \\ \mathrm{h} & =\text { altitude } \\ \mathrm{M} & =\text { Mach number } \\ \mathrm{MSL} & =\text { mean sea level } \\ \mathrm{t} & =\text { time } \\ \mathrm{TPS} & =\text { Thermal Protection System } \\ \text { UTTR } & =\text { Utah Test and Training Range }\end{array}$

\section{Introduction}

STARDUST, the fourth of NASA's Discovery class $\checkmark$ missions, was launched on February 7, 1999. The spacecraft performed a close flyby of the comet Wild-2. It came within $149 \mathrm{~km}$ of the comet nucleus deploying a sample tray to collect cometary and interstellar particles (Fig. 1). Stardust was the first mission to return samples from a comet. Upon Earth return on the morning of January 15, 2006 at 09:56:42.3 UTC, the entry capsule, containing the comet samples, was released from the main spacecraft and successfully landed by parachute in northwest Utah at the U.S. Military's Utah Test and Training Range (UTTR). A detailed overview of the Stardust mission is provided in Reference 1. The Earth return maneuver and targeting procedures prior to entry

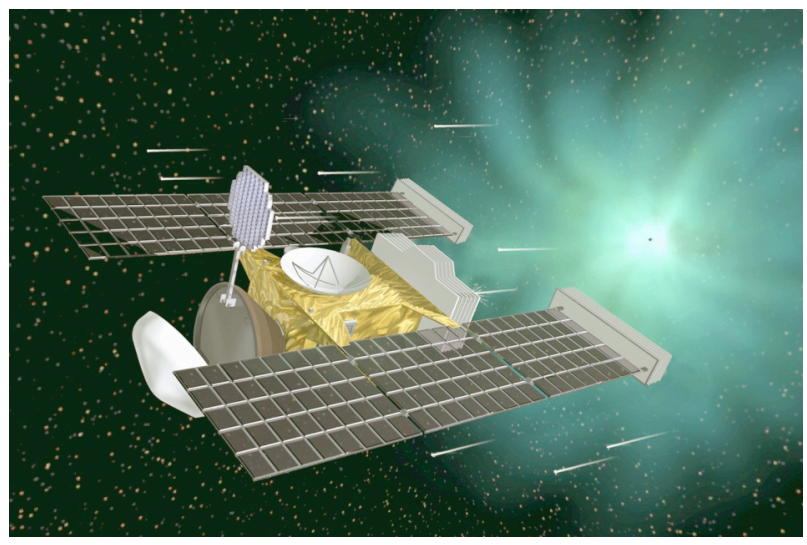

Figure 1. Stardust spacecraft sample acquisition configuration.

*Senior Engineer, Atmospheric Flight \& Entry Systems Branch, 1 N. Dryden St., MS 489, prasun.n.desai@nasa.gov, AIAA Associate Fellow.

${ }^{\dagger}$ Senior Engineer, Advanced Engineering Environments Branch, 1 N. Dryden St., MS 458, garry.d.qualls@nasa.gov. 
interface were nominal and placed the capsule on the desired flight path required for a successful entry. ${ }^{2,3}$ The nominal design values at entry interface (radius of $6503.14 \mathrm{~km}$ ) for the inertial entry velocity and inertial flight-path angle for the Stardust capsule were $12.9 \mathrm{~km} / \mathrm{s}$ and $-8.2 \mathrm{deg}$, respectively.

Four hours prior to entry, the $46 \mathrm{~kg}$ Stardust capsule was spun-up to $13.5 \mathrm{rpm}$ and separated from the main spacecraft. The capsule had no active guidance or control system, so the spin-up was required during coast to atmospheric interface to maintain its entry attitude (nominal 0 deg angle-of-attack). Figure 2 illustrates the nominal entry sequence. Throughout the atmospheric entry, the passive capsule relied solely on aerodynamic stability to perform a controlled descent through all aerodynamic flight regimes: free molecular, hypersonic-transitional, hypersonic-continuum, supersonic, transonic, and subsonic. ${ }^{4}$ Therefore, the capsule was required to possess sufficient aerodynamic stability to minimize any angle of attack excursions during the severe heating environment. Additionally, this stability was needed throughout the transonic and subsonic regimes to maintain a controlled attitude at drogue and main parachute deployments.

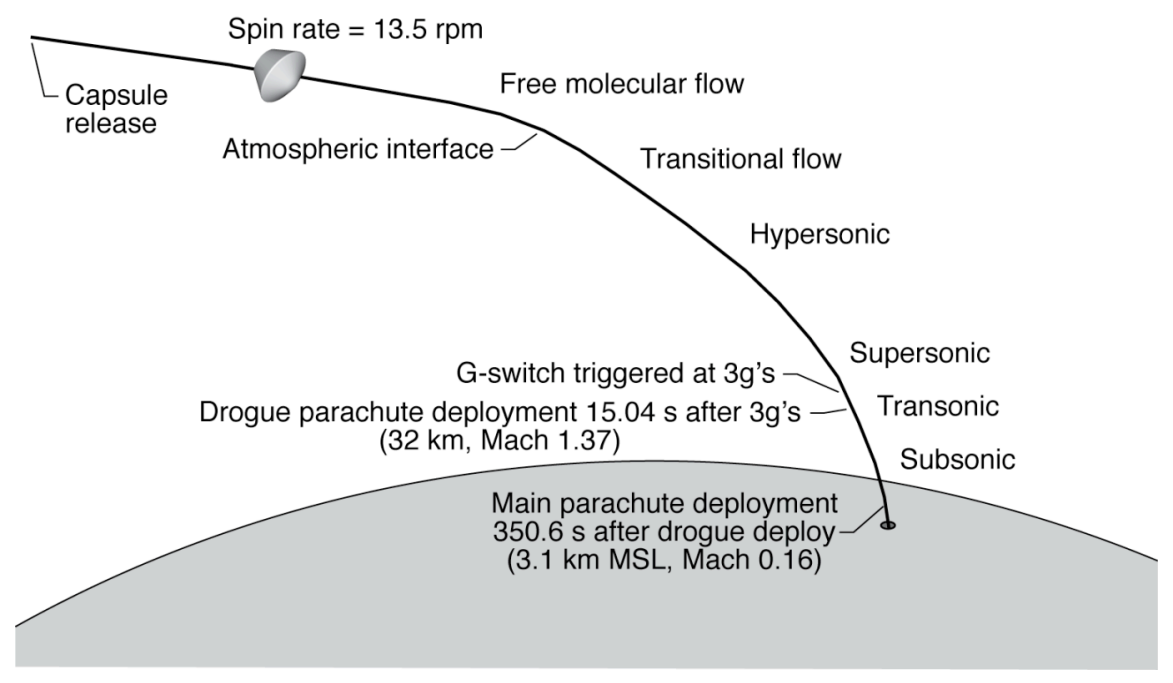

Figure 2. Nominal Stardust capsule entry sequence.

During the nominal entry design sequence, a G-switch was utilized to initiate a timer for drogue deployment. At $15.04 \mathrm{~s}$ after the G-switch sensed a $3 \mathrm{~g}$ deceleration, the supersonic drogue parachute would be deployed at approximately Mach 1.37 and a mean sea level (MSL) altitude of $32 \mathrm{~km}$, where a second timer would be initiated for triggering main parachute deployment. After $350.6 \mathrm{~s}$ (approximately Mach 0.16 and an MSL altitude of $3.1 \mathrm{~km}$ [1.8 $\mathrm{km}$ above ground]), the main parachute would be deployed to slow the capsule for landing at UTTR. The second timer was the primary method for main parachute deployment. However, due to the long descent time of $350.6 \mathrm{~s}$ to main deployment, and concerns about the uncertainty in the combined aerodynamics of the capsule and drogue parachute, a backup method was incorporated for main parachute deployment that utilized an onboard pressure transducer (i.e., a baroswitch). The trigger value for the transducer was pre-set to deploy the main parachute at a sensed pressure of $10.11 \mathrm{psi}$, which corresponds to a nominal altitude of $3.1 \mathrm{~km}$ MSL (10,000 ft). The accuracy of this transducer triggering process was $\pm 0.73 \mathrm{~km}( \pm 2400 \mathrm{ft})$ based on pre-flight analyses. The primary uncertainty was a known temperature dependency in the pressure transducer and associated electronics of the avionics unit. This nominal entry sequence was sufficiently robust to accommodate off-nominal conditions during the descent as demonstrated by the Monte Carlo dispersion analyses described in Refs. 3 and 4.

This paper provides an overview of the reconstruction analysis performed for the Stardust capsule entry to quantify how well the pre-entry predictions compared to the actual descent. First, a comparison of the atmospheric properties (density and winds) encountered during the entry to the pre-entry profile is presented. An analysis that was performed on video footage (obtained from the radar tracking stations at UTTR) during the descent is then described for determining the times for drogue and main parachute deployments. Next, the entry trajectory reconstruction that was performed is described providing an understanding of how well the actual entry compared to the nominal sequence outlined in Fig. 2. Lastly, an assessment of the Stardust capsule hypersonic attitude that must have occurred during the entry is presented based on examination of the recovered capsule heatshield. This effort follows the entry reconstruction process that was developed for the Genesis capsule, since the entry, descent, and landing design for the two missions was very similar. ${ }^{5}$ 


\section{Final Landing Location}

Using the final orbit determination results, ${ }^{3}$ the pre-entry nominal landing location was predicted to be $5.7 \mathrm{~km}$ south-southwest from the desired target as indicated in Fig. 3, with a $99 \%$ footprint ellipse of $45.1 \mathrm{~km}$ by $19.2 \mathrm{~km}$. Based on these results, the authorization for capsule separation four hours prior to Earth entry was granted. However, on entry day of January 15, 2006, a sever winter storm was moving through western Utah. Balloon measurement data at entry minus 2 hours (E-2 hr) revealed that very strong sustained winds (discussed in the next section) were present over UTTR arising from a winter blizzard. Consequently, an updated prediction of the landing location using the E-2 $\mathrm{hr}$ balloon measured wind data was necessitated to aid the Stardust recovery team for retrieving the capsule. Figure 3 shows the updated prediction to the nominal landing location, along with an updated $99 \%$ footprint ellipse. Reference 3 provides an in depth overview of the entry analysis performed during return flight operations.

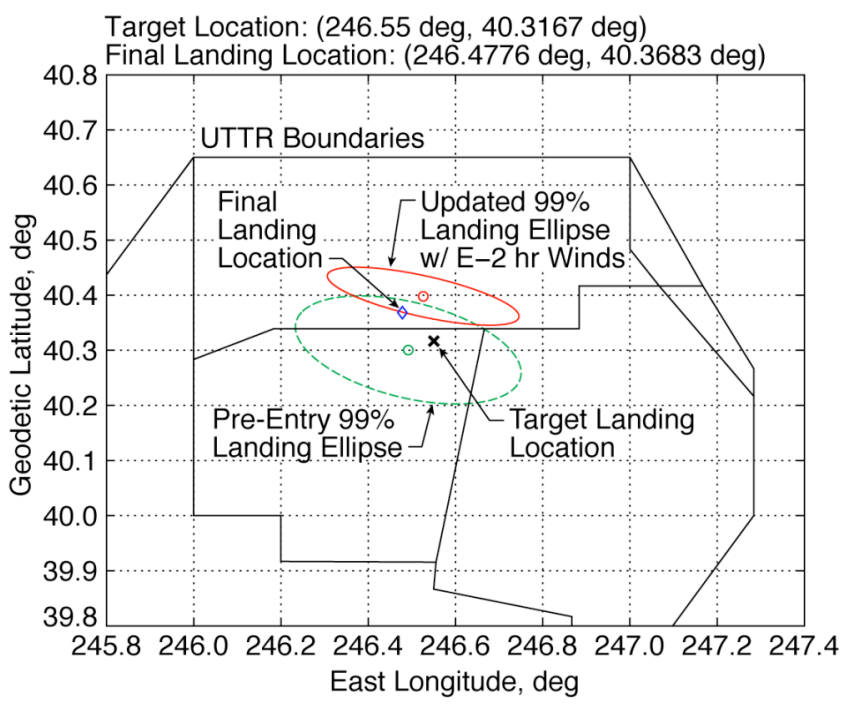

Figure 3. Final capsule landing location.

As seen in Fig. 3, the pre-entry landing prediction shifted north due to the sustained winds indicated by E- $2 \mathrm{hr}$ balloon measurement wind data. The predicted nominal landing location moved from $5.7 \mathrm{~km}$ west-southwest of the target (green circle) to $9.4 \mathrm{~km}$ north-northwest of the target (red circle). The updated $99 \%$ footprint ellipse was 38.1 $\mathrm{km}$ by $8.2 \mathrm{~km}$ having an azimuth orientation angle of 102.9 deg (measured clockwise positive from North). The sustained northward wind shifted the predicted nominal landing location approximately $11.5 \mathrm{~km}$ almost due north. The final Stardust capsule landing location (blue diamond) was $8.1 \mathrm{~km}$ north-northwest of the desired target as shown in Fig. 3. This landing location was within the pre-entry predicted $99 \%$ landing ellipse. The final landing location shows that the capsule had not drifted as much to the north as the updated prediction. This outcome was undoubtedly a result of the winds subsiding (as forecasted) from the balloon measured data at E- $2 \mathrm{hr}$, which were used in the updated prediction.

Although the Stardust capsule landed very close to the pre-entry predicted landing location, an understanding of the hypersonic flight is of great interest to gain confidence in the design principles and methodologies that are utilized during the design and development phases of entry vehicles. The subsequent sections provide an overview of the Stardust capsule entry reconstruction effort.

\section{Atmosphere Comparison}

The Earth atmosphere model utilized by Stardust for the entry trajectory design and analysis was the Global Reference Atmospheric Model - 1995 Version (GRAM-95). ${ }^{6}$ This model is an amalgam of three empirically based global atmospheric data sets of the Earth that can produce an atmosphere profile as a function of altitude for a given date, time, and positional location about the Earth. GRAM-95 produces a representative atmosphere taking into account variations in diurnal, seasonal, and positional information for a given trajectory to produce nominal density, temperature, pressure, and wind profiles, and their statistical perturbations along the trajectory flight track. GRAM95 is not a predictive model. A profile is generated based on historical data for a given date, time, and location.

Two hours prior to the Stardust capsule entry, a balloon was launched from UTTR to obtain measurements of the atmospheric properties over the range. The balloon measured density data is plotted in Fig. 4 as a percentage of the 
nominal profile obtained from the GRAM-95 model. That is, if the balloon measured density was identical to the GRAM-95 profile, a vertical line at a value of 1.0 would result. Note, measurements were only available for altitudes up to $30 \mathrm{~km}$. Also depicted in Fig. 4 are the upper and lower 3- $\sigma$ boundaries of the possible density variation (as a percentage of the GRAM-95 nominal profile) produced by the GRAM-95 model for the Stardust entry date and time. As seen, the balloon measured density for altitudes between 17-30 km falls within the $\pm 3-\sigma$ GRAM-95 bounds, being just a few percent lower. Below $17 \mathrm{~km}$, the balloon measured density variation increased, and in the region between approximately $11-13 \mathrm{~km}$ exceeded the 3- $\sigma$ low GRAM-95 values. The maximum deviation in the atmospheric density between the E-2 hr balloon measurement data and the GRAM-95 model was approximately $6 \%$ at an altitude near $11 \mathrm{~km}$. For altitudes above $30 \mathrm{~km}$, no measurement data was available.

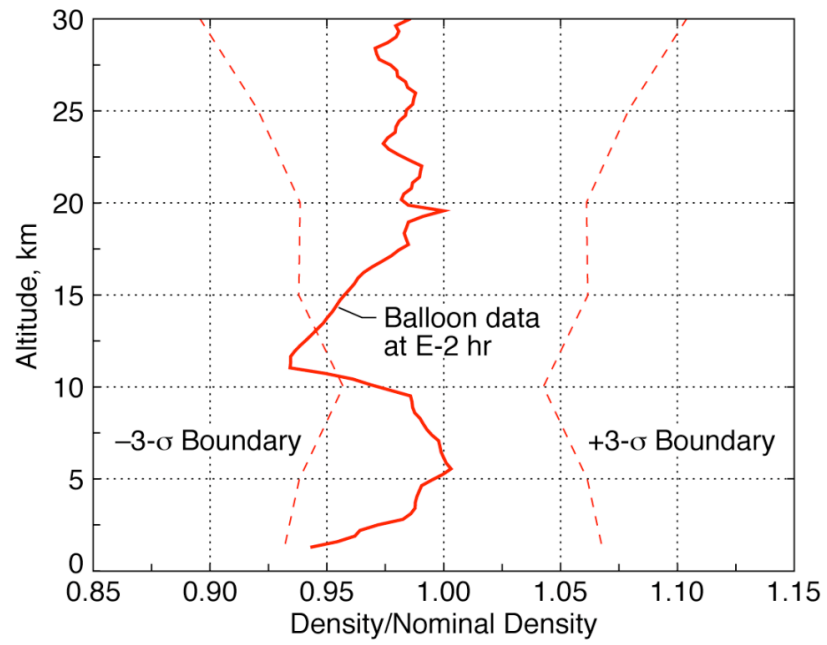

Figure 4. Density comparison to GRAM-95 model.

Similarly, balloon measured wind data for the northward and eastward wind components are shown in Figs. 5 and 6. Also indicated in these figures are the nominal profiles produced by the GRAM-95 model, as well as their respective upper and lower 3- $\sigma$ boundaries. As seen, the balloon measured northward wind component showed a sustained wind (previously alluded to) having a peak wind speed of $50 \mathrm{~m} / \mathrm{s}$ at approximately $10 \mathrm{~km}$. This sustained wind pushed the capsule to the north while it descended under the parachutes. This balloon measured northward wind component corresponded to nearly a $+3-\sigma$ high profile as compared to the GRAM-95 model. The measured eastward wind component is shown in Fig. 6, and was observed to be very close to the nominal profile produced by GRAM-95.

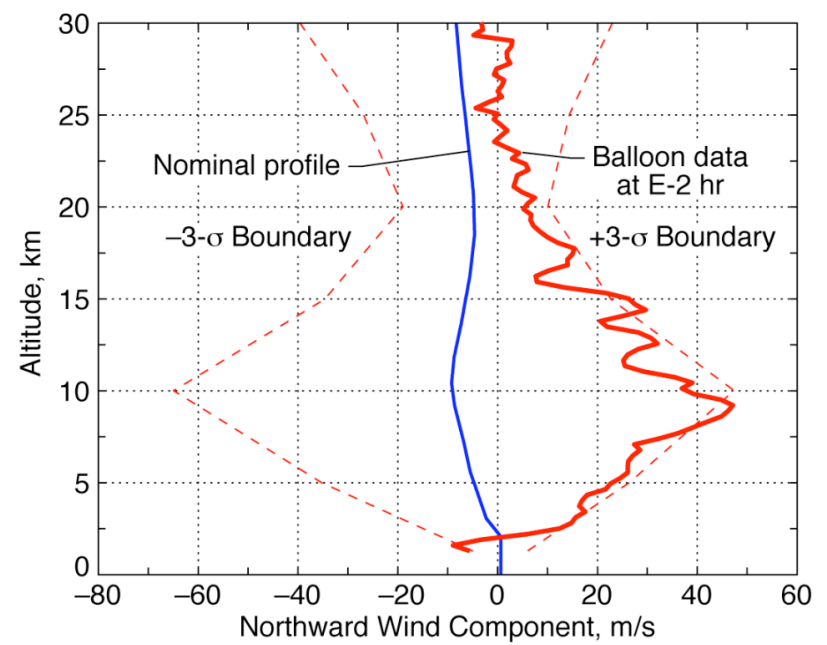

Figure 5. Northward wind component comparison to GRAM-95 model. 


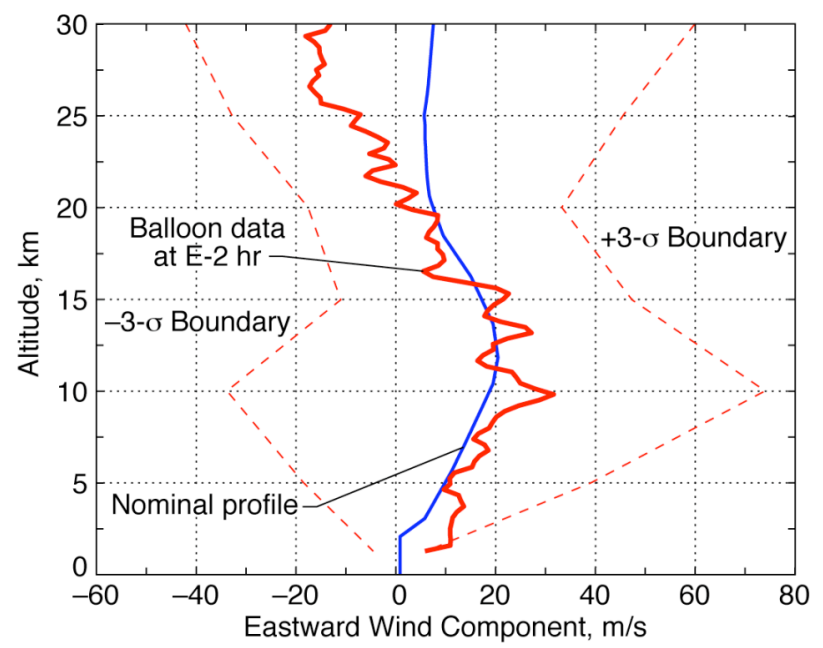

Figure 6. Eastward wind component comparison to GRAM-95 model.

\section{Video Analysis for Determining Deployment Times}

Since there were no on board sensor data from which to perform a "traditional" reconstruction for the Stardust capsule during entry, video footage obtained from the UTTR radar tracking stations was employed to assess the deployment times of the drogue and main parachutes.

Several visible and infrared cameras that were a part of the UTTR infrastructure videotaped the Stardust capsule descent from approximately $35 \mathrm{~km}$ to landing. Videotapes from all of the cameras were reviewed to determine whether they would provide insight into technical details of the capsule's flight. Two videotapes that captured the two parachute deployments were selected for analysis, in conjunction with radar range data obtained from tracking the capsule as it descended.

The deceleration profile for the capsule obtained from the radar range data set is shown in Fig. 7. Unfortunately, there were no clear features in the profile to suggest or depict the precise times for drogue and main parachute deployments. As a result, footage from the two videotapes that captured both deployments was utilized to aid the determination of the deployment times. Drogue parachute deployment occurred at 09:59:00.2 UTC, which was $137.9 \mathrm{~s}$ after entry. This time was $4.8 \mathrm{~s}$ later than the nominal pre-entry predicted time of $133.1 \mathrm{~s}$. However, this delayed drogue deployment time was within the expected variation of $\pm 7.4 \mathrm{~s}$ calculated from Monte Carlo dispersion analyses. ${ }^{3,4}$ The corresponding Mach number (M) and altitude (h) at drogue deployment were 1.23 and $31.03 \mathrm{~km}$ MSL, respectively, which were a little lower than the nominal pre-entry predicted values outlined in Fig. 2.

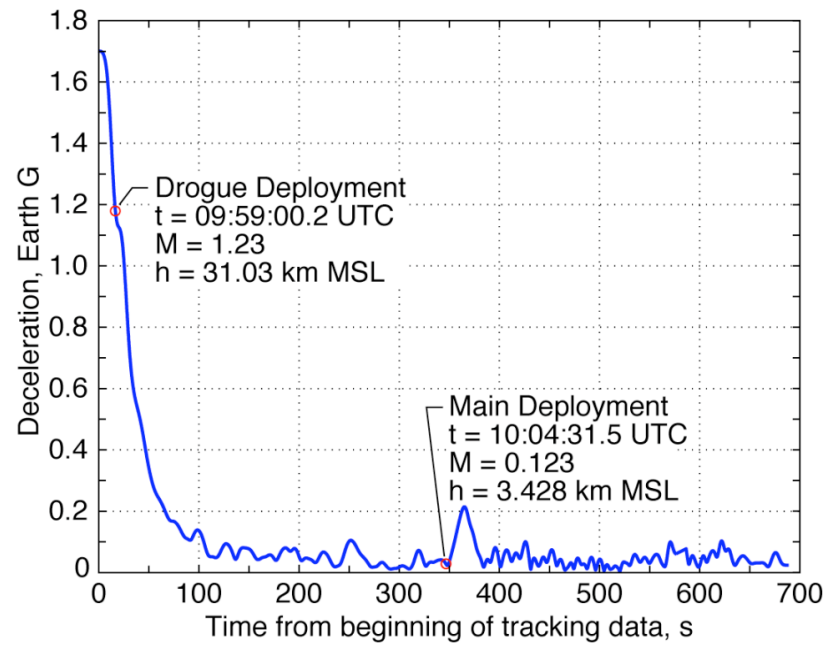

Figure 7. Capsule deceleration profile from radar tracking data. 
Main parachute deployment occurred at 10:04:31.5 UTC, which was 331.3 s after drogue deployment. This time was $19.3 \mathrm{~s}$ earlier than the pre-set timer setting of $350.6 \mathrm{~s}$ as outlined in Fig. 2. This earlier main deployment time indicated that main parachute deployment was actually triggered by the backup baroswitch. The corresponding altitude of $3.428 \mathrm{~km}$ MSL was $0.328 \mathrm{~km}$ higher than the pre-entry predicted nominal $3.1 \mathrm{~km}$ MSL altitude, but was within the known variation of the baroswitch triggering process. As previously mentioned, this variation was due to a known temperature dependence in the pressure transducer and associated electronics. The capsule avionics unit temperature was passively controlled during its flight through the use of thermal blankets. This approach resulted in a predicted design temperature range during entry and descent of $-25 \mathrm{deg} \mathrm{C}$ to $+35 \mathrm{deg} \mathrm{C}$. The nominal deploy setpoint was for a temperature of $+10 \mathrm{deg} \mathrm{C}$. The design temperature range was shown analytically to vary the main deployment altitude by roughly $+0.52 \mathrm{~km}$ (for a $-25 \mathrm{deg} \mathrm{C}$ cold unit) to $-0.35 \mathrm{~km}$ (for a $+35 \mathrm{deg} \mathrm{C}$ warm unit). The observed $3.428 \mathrm{~km}$ MSL main deployment altitude was $0.328 \mathrm{~km}$ higher than nominal, but still well within the system accuracy of $\pm 0.73 \mathrm{~km}$. If ascribed to temperature alone, this altitude offset would correspond to an estimated avionics unit temperature at main deployment of $-10 \operatorname{deg} \mathrm{C}$, somewhat colder than nominal, but well within the range of pre-flight predictions.

An attempt was made to further utilize the infrared video footage to assess the Stardust capsule attitude information, as was successfully performed for the Genesis capsule entry reconstruction effort. Reference 5 provides an in depth description of the process of using luminance data from the infrared footage to extract capsule attitude during the Genesis entry. Unfortunately, the infrared video footage of the Stardust entry was not of the same quality as that for Genesis, and prevented separating the luminance data from noise. As such, no quantitative attitude information could be extracted from the video footage for the Stardust capsule. However, a qualitatively capsule attitude assessment is provided in the last section based on examination of the recovered heatshield.

\section{Trajectory Reconstruction}

Since, there were no on board accelerometer or gyro sensor data from which to perform a "traditional" trajectory reconstruction for the Stardust capsule entry, a Best Estimated Trajectory (BET) was calculated. For the estimate of the hypersonic portion of the flight, only two data sets were available, namely the final navigation state vector at entry interface and radar range data from the UTTR tracking stations. Therefore, the BET was based on using the final navigation state vector at entry interface and the latitude and longitude data (obtained from the UTTR radar range data set) at the actual drogue deployment time of 09:59:00.2 UTC estimated in the previous section (which was calculated to be $137.9 \mathrm{~s}$ after entry interface). The UTTR radar tracking stations acquired the capsule from an altitude of approximately $35 \mathrm{~km}$ through landing. The accuracy of the navigation state vector at entry interface was confirmed by tracking data obtained from Strategic Command (STRATCOM) to be near nominal with very small errors (well within $0.5-\sigma){ }^{3}$ In addition, the UTTR radar tracking station data set also had small errors.

With confidence in these two end points (one at entry interface and the other at the actual drogue deployment time), a hypersonic trajectory was calculated employing the trajectory simulation utilized for the pre-entry predictions. ${ }^{3,4}$ Within this trajectory simulation, a multiplier on the capsule aerodynamic drag was applied as the control parameter in an effort to determine what capsule drag variation was needed to match the two end point conditions. This aerodynamic drag multiplier value, if accurate, should produce an altitude that would be close to that obtained by the UTTR radar range data set at the actual drogue deployment time. An increase in the capsule aerodynamic drag of only $0.83 \%$ (from the baseline nominal value) produced an entry trajectory profile that matched the altitude at the actual drogue deployment time point very well. The altitude difference from this BET was extremely close within $3 \mathrm{~m}$ to that obtained from the UTTR radar range data set. The UTTR radar range data set indicated an altitude of $31.03 \mathrm{~km}$ MSL, while the BET produced an altitude of $31.033 \mathrm{~km}$ MSL. The corresponding Mach number was also very close, within a value of 0.02 ; the UTTR radar range data set indicated $\mathrm{M}=1.23$, while the BET produced $M=1.213$. Since the aerodynamic drag multiplier was so small (less than $1 \%$ ), the actual Stardust entry was very close to the nominal pre-entry prediction. Figure 8 shows the altitude and planet-relative velocity profile from the BET, which is indistinguishable from the pre-entry predicted trajectory profile.

The maximum deceleration calculated from the BET was 32.89 Earth $\mathrm{g}$ as compared to 32.86 Earth $\mathrm{g}$ obtained from the nominal pre-entry predicted trajectory. The 3- $\sigma$ variation in the maximum deceleration from the final preentry Monte Carlo analysis was \pm 3.64 Earth g. ${ }^{3}$ Hence, the actual Stardust capsule entry was very close to pre-entry predicted nominal, and well within the 3- $\sigma$ dispersions. Consequently, the aerodynamic drag and peak heat rate experienced during the entry must have been very close to the nominal environment predicted during the design phase. 


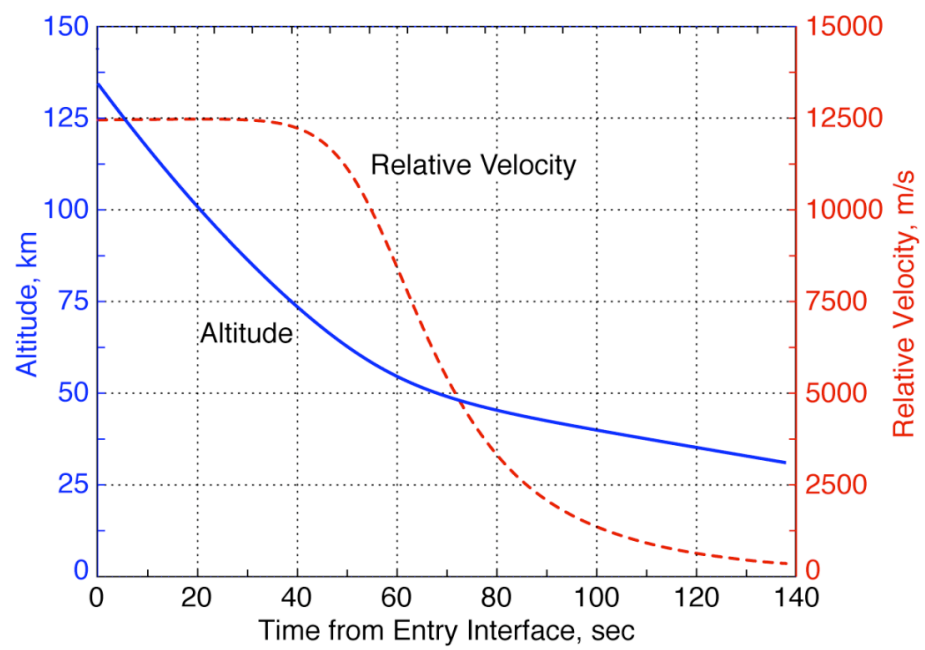

Figure 8. Altitude and planet-relative velocity profiles from the BET.

The parachute descent portion of the flight was obtained from the UTTR radar range data set and is depicted in Fig. 9. As seen, after drogue deployment at $31 \mathrm{~km} \mathrm{MSL}$, the capsule continues the descent along its entry azimuth of 102.9 deg (i.e., in an east-southeast direction). Starting at approximately $10 \mathrm{~km} \mathrm{MSL}$, the high sustained northward wind previously alluded to pushed the capsule towards the north as seen by its increasing geodetic latitude. The capsule continued its descent along a northward track through main parachute deployment at $3.428 \mathrm{~km}$ MSL until final landing.

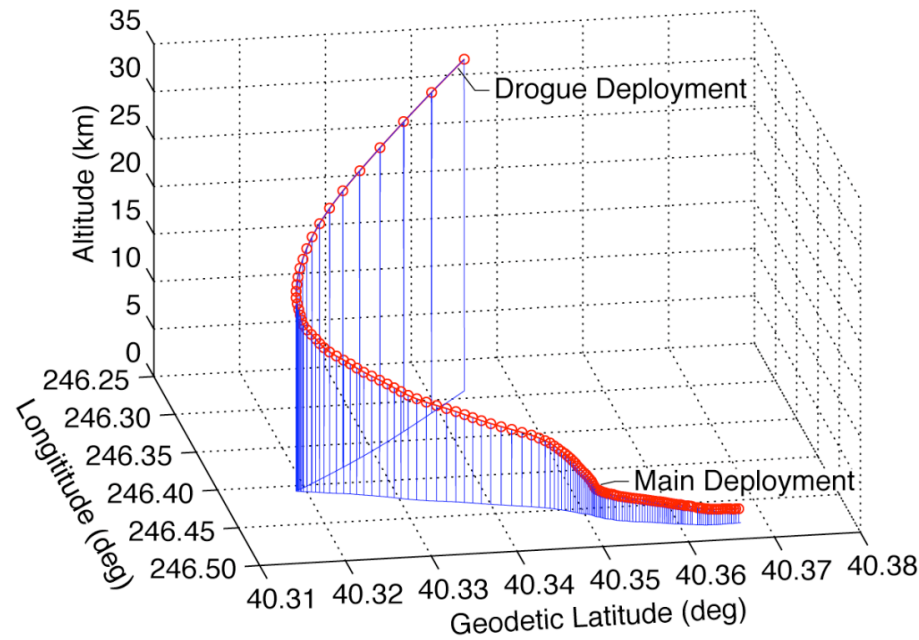

Figure 9. Capsule descent profile on parachute.

\section{Hypersonic Attitude Assessment}

Since there was no on-board accelerometer or gyro sensor data, the capsule hypersonic attitude behavior cannot be calculated. Therefore, the attitude during the hypersonic flight must be inferred from observations of the recovered capsule forebody and aftbody heatshield material response. As seen in Fig. 10, there was very little, if any, charring of the shoulder region or the aftbody Thermal Protection System (TPS) material. Also, inspection of the forebody TPS (Fig. 11) shows charring patterns that imply symmetric heating. 




Figure 10. Image of capsule shoulder region and aftbody heatshield.



Figure 11. Image of capsule forebody heatshield.

These observations suggest that the capsule attitude must have been only a few degrees during hypersonic flight. The pre-entry trajectory simulations predicted a nominal capsule angle of attack during the hypersonic phase near peak heating of $2.4 \mathrm{deg}$ with a $+3-\sigma$ high value of $5.1 \mathrm{deg}$. Consequently, the observations of the heatshield corroborate the pre-entry attitude predictions and support the estimates of small hypersonic angles of attack. These observations support the assertion that the aerodynamic database (see Ref. 7) generated for the Stardust capsule reasonable predicted the static stability in the hypersonic regime. In summary, while no definitive claims can be made because of the limited flight data, there are no indications in the available data to suggest that the Stardust capsule aerodynamic performance deviated significantly from the pre-entry nominal predictions.

\section{Conclusion}

On the morning of January 16, 2006, the Stardust capsule entered and descended through the Earth's atmosphere successfully landing under parachute at the Utah Test and Training Range completing a seven year journey around the solar system. The capsule landed $8.1 \mathrm{~km}$ north-northwest of the desired target. A reconstruction analyses for the Stardust capsule entry was performed.

The results indicate that the actual entry was very close to the pre-entry predictions. Atmospheric properties (density and winds) encountered during the entry based on balloon measurements were in general within the a priori variations predicted. However, due to a winter blizzard that occurred during entry, a sustained northward wind was present having a peak speed of $50 \mathrm{~m} / \mathrm{s}$. This measured northward wind (corresponding to a $+3-\sigma$ high profile compared to the nominal prediction) pushed the capsule towards the north from the desired target. Infrared video footage and radar range data obtained from tracking stations during the descent were used to estimate the times of drogue and main parachute deployments. Drogue parachute deployment was $4.8 \mathrm{~s}$ later than the pre-entry prediction, which was well within the expect variation of $\pm 7.4 \mathrm{~s}$. Main parachute deployment was $19.3 \mathrm{~s}$ earlier than the pre-set timer indicating that main deployment was actually triggered by the backup baroswitch. The altitude for main deployment was $3.428 \mathrm{~km}$ MSL. Reconstruction of a best estimated trajectory revealed that the aerodynamic drag experienced by the capsule during hypersonic flight was within $1 \%$ of pre-entry predications. Consequently, the aerodynamic drag and peak heat rate experienced during hypersonic flight were very close to the nominal environment predicted during the design phase. Since there was no on-board accelerometer or gyro sensor data, capsule attitude during hypersonic flight could not be calculated, and therefore, was inferred from observations of the recovered heatshield. Observations of the heatshield support the pre-entry estimate of small hypersonic angles of attack, since there was very little, if any, charring of the shoulder region or the aftbody indicating that the aerodynamic database generated for the Stardust capsule reasonably predicted the static stability during hypersonic flight.

In summary, while no definitive claims can be made because of the limited flight data, there were no indications in the available data set to suggest that the Stardust capsule aerodynamic performance deviated significantly from the pre-entry nominal predictions. Through this investigation, an overall assertion can be made that all the data gathered from the Stardust entry (radar range tracking data, balloon measurement, video footage, and post-landing capsule hardware inspection) were consistent with flight performance close to nominal pre-entry predictions. Consequently, the design principles and methodologies utilized for the Stardust flight dynamics, aerodynamics, and aerothermodynamics analyses have been corroborated. 


\section{References}

${ }^{1}$ Atkins, K. L., Brownlee, D. E., Duxbury, T., Yen, C. W., Tsou, P., and Vollinga, J. M., "STARDUST: Discovert's InterSteller Dust and Cometary Sample Return Mission," 1997 IEEE Aerospace Conference, Proceeding Vol. 4 (A97-44051 1299), Apsen, CO, February1997, pp. 229-245.

${ }^{2}$ Helfrich, C., Bhat, R., Kangas, J., Wilson, R., Wong, M., Potts, C., and Williams, K., "Maneuver Analysis and Targeting Strategy for the Stardust Re-Entry Capsule," AIAA-2006-6406, AIAA/AAS Astrodynamics Specialists Conference and Exhibit, Keystone, Co., Aug. 2006.

${ }^{3}$ Desai, P. N., Lyons, D. T., Tooley, J., and Kangas, J., "Entry, Descent, and Landing Operations Analysis for the Stardust Re-Entry Capsule," AIAA-2006-6410, AIAA/AAS Astrodynamics Specialists Conference and Exhibit, Keystone, Co., Aug. 2006.

${ }^{4}$ Desai, P. N., Mitcheltree, R. A., and Cheatwood, F. M., "Entry Dispersion Analysis of the Stardust Sample Return Capsule," Journal of Spacecraft and Rockets, Vol.36, No. 3, May-June 1999, pp. 463-469.

${ }^{5}$ Desai, P. N., Qualls, G. D., Schoenenberger, M., "Reconstruction of the Genesis Entry," Paper No. GT-SSEC.C.1, George Tech School of Aerospace Engineering Conference, Atlanta, GA, Oct. 2005.

${ }^{6}$ Justus, C. G., Jeffries III, W. R., Yung, S. P., and Johnson, D. L., "The NASA/MSFC Global Reference Atmospheric Model 1995 Version (GRAM-95),"NASA TM-4715, Aug. 1995.

${ }^{7}$ Mitcheltree, R. A., Wilmoth, R. G., Cheatwood, F. M., Brauckman, G. J., and Greene, F. A., "Aerodynamics of the Stardust Sample Return Capsule," AIAA Paper 97-2304, June 1997. 